\title{
ERRATA
}

\section{ELASTIC CONSTANTS OF ORTHORHOMBIC SULPHUR}

\author{
BY R. V. G. SUNDARA RAO
}

IN a paper published in these Proceedings (Rao, 1950), the author had reported the results of measurements of the determination of the elastic constants of orthorhombic sulphur.

Due to oversight, in converting the elastic constants $\mathrm{C}_{i j}$ into the compliances $s_{i j}$, a systematic mistake crept into the latter.

The following are the correct values of $s_{i j}$ corresponding to the $\mathrm{C}_{i j}$ given on page 275 in the above article:-

$$
\begin{array}{ccr}
s_{11}=70.9 & s_{22}=83.4 & s_{44}=232 \\
s_{12}=-35.6 & s_{23}=-14.9 & s_{55}=115 \\
s_{13}=-13.4 & s_{33}=30 \cdot 3 & s_{66}=132 \\
& \beta=56 \cdot 8 \times 10^{-13} \mathrm{~cm}^{2}{ }^{2} \text { dyne }^{-1}
\end{array}
$$

The above are in units of $\mathrm{cm} .{ }^{2} /$ dyne.

The error was pointed out by Dr. W. A. Wooster to whom the author's thanks are due.

\section{REFERENCES}

Sundara Rao, R. V. G. . . Proc. Ind. Acad. Sci., Sec. A, 1950, 32, 275.

Vol. XL, Section A, No. 2, August 1954

In the graph on page 103 the portions corresponding to 0 to 50 days may be ignored. 